\title{
The hydrodynamic response of a semi-arid headwater wetland to technical rehabilitation interventions
}

\author{
ES Riddelli*, SA Lorentz ${ }^{1}$ and DC Kotze ${ }^{2}$ \\ ${ }^{1}$ School of Bioresources Engineering and Environmental Hydrology, University of KwaZulu-Natal, Private Bag X01, \\ Scottsville, Pietermaritzburg 3209, South Africa \\ ${ }^{2}$ Centre for Environment and Development, University of KwaZulu-Natal, Private Bag X01, Scottsville, Pietermaritzburg 3209, \\ South Africa
}

\begin{abstract}
Loss of wetland extent continues to be documented as a significant problem and this is true for the headwaters of the Sand River system in the north-east of South Africa. Here wetlands are undergoing severe down-cutting by erosion gullies (dongas) leading to desiccation of the system and loss of viable substrate that is used for subsistence agriculture. The Manalana sub-catchment was the focus of an integrated wetland rehabilitation programme between 2004-2009, a major focus of which was the stabilisation of such erosion gullies by large retaining structures. This paper presents findings of a hydrological monitoring study of the shallow groundwaters to determine the wetland's hydrodynamic behaviour and the extent to which this had degraded as a result of erosion. Furthermore, whether technical rehabilitation could ameliorate any degradation in the wetland's hydrological condition was also assessed. The findings show that the wetland groundwater hydrology is strongly controlled by the distribution of clays within it, facilitating distinct hydrological micro-regions within the wetland spatially and vertically. Based on these findings it is revealed that the loss of these clays impacts severely on the system's hydrology. The installation of an impermeable buttress weir was able to restore these hydrodynamics as observed through the reversal of the hydraulic gradients between groundwater observation stations, but the precise placement of the structure was shown to be crucial for this effect. This finding demonstrated the requirement of informed, or wise, technical rehabilitation principles based on hydro-geomorphic understanding of the system. A downstream pervious gabion dam was also monitored for its effect on restoring the wetland's hydrology, but observed responses showed little change, and, in fact, the wetlands hydrology here remained intact, attributed to the presence of a clay plug that was saved from erosion by the placement of this structure.
\end{abstract}

Keywords: wetlands, rehabilitation, phreatic surface, piezometer, aquitard

\section{Introduction}

Wetland loss through erosion and conversion to alternative land uses in South Africa is extensive, and within several major catchments of the country some $35-60 \%$ loss of wetland extent has been experienced (Dada et al., 2007). This loss may have significant implications for streamflow regulation processes given that wetlands are thought to be important for base-flow augmentation and flood peak attenuation, although these are still poorly understood phenomena (e.g. Bullock and Acreman, 2003). Wetlands within the savanna biome of sub-Saharan Africa are well utilised due to the potential, if properly managed, for diverse crop productivity and an array of other direct and indirect benefits. A wetland's economic and hydrological values were recognised as key factors that engender the need for their management by integrated means (Scoones, 1991). Nevertheless, wetlands continue to play a crucial role in livelihood security for a large part of the rural South African population and were most often not stringently subject to 'best management practices' and adequate governance systems that facilitate sustainable use of these environmental resources (Kotze and Silima, 2003). Wetland degradation thus poses a serious threat to the country's water and livelihood-sustaining resources.

\footnotetext{
* To whom all correspondence should be addressed.

용 +27 72337 1274; fax: +27 87 575-7542;

e-mail: riddelle@ukzn.ac.za

Received 8 March 2011; accepted in revised form 14 December 2011.
}

'Wetland rehabilitation' has recently been put forward, particularly within South Africa, as the process by which one seeks to re-establish ecological driving forces within part or the whole of a degraded wetland to recover former or desired ecosystem structure, function, biotic composition and/or ecosystem services (Grenfell et al., 2007). Since it is the hydroperiod, or temporal pattern of wetland water levels, such as seasonal variations in hydrological inputs and outputs from the system, which is the criterion for characterising each wetland type (Mitsch and Gosselink, 2007), this is what needs to be restored when rehabilitating a wetland whose hydrological regime has been altered. It is the hydrodynamics, or the ability of water to do work, specifically the direction and force of flow (Brinson, 1993), that controls the water storage of the system, as well as allogenic factors such as climate that define the wetland's hydroperiod. Monitoring of a wetland's hydrodynamics, such as water table depths, can reveal important insights into the likely response of wetland sites to changes in their contributing area as well as in-situ impacts whether they be natural or artificial (e.g. Gilman, 1994; Dixon 2002; Voldseth et al., 2007). Furthermore these approaches were useful for tracking the trajectory of attempts to restore a wetland's hydrology (Moorhead, 2003). Monitoring the hydrodynamics of wetlands is also useful for quantifying the extent of wetland degradation, as has been characterised for communally-used wetlands in Ethiopia (Conway and Dixon, 2000).

This study, initiated in 2005, was in response to the technical rehabilitation, on a larger scale, of erosion gullies which were deemed to be threatening the integrity of the wetlands 
within the headwaters of the Sand River system. The majority of these headwater catchments, situated within the foothills of the Klein Drakensberg escarpment, provide considerable livelihood benefits for local communities in terms of wet and dry season agriculture. Unwise cultivation practices by local land-users, such as the creation of deep drainage furrows, poor tillage, and poor vegetative cover, were seen to be contributing in large part to the degradation of these systems (Pollard et al., 2005). This is exacerbated by the huge demand for wetland agricultural space in this former 'homeland' area that was subject to enforced settlement (1960s onwards). This population pressure compounds the fact that the soils in these wetlands are inherently unstable, predominantly coarse sands, and in a region subject to very intense storm events. These wetlands were also assumed to be crucial for flow regulation (attenuation and augmentation) of the now degraded Sand River, the main tributary of the perennial Sabie River, serving the Kruger National Park (Pollard et al., 2005). Furthermore, the development of the gully networks, or at the very least their continued movement, was attributed to these unwise cultivation practices that may well increase surface water discharges within the wetlands themselves (Pollard et al., 2005). In addition, certain land-use practices within the contributing catchments, such as overgrazing and densely-populated housing, including a dense network of hardened surfaces in the form of roads and pathways, were also a contributing factor. Similar phenomena have been experienced with wetland processes and gully erosion associations in other degraded landscapes (e.g. Whitlow, 1989; McFarlane and Whitlow, 1991; McHugh et al., 2007).

Whilst there appears to be scant information in the academic literature surrounding hydrological restoration with respect to technical rehabilitation of eroded wetlands in general, there have been a few specific studies that allow for a certain degree of contextualisation. These have for the most part examined the hydrological response of temperate wetlands with organically rich soils to reversion of management practices such as blocking of drainage ditches. For instance, Patterson and Cooper (2007) showed that fen water tables could successfully be restored by rehabilitation (blocking) of roadinduced drainage ditches, which in this instance was ascribed to the raising of the mean water table in the fen during the postrehabilitation period and the concomitant recovery of peatlandassociated plant species in following seasons. Meanwhile, Price et al. (2003) suggested that degraded mined peatlands do not recover well given the degradation of subsurface Sphagnum. However, blocking of drainage ditches would lead to stabilisation of the peatland's water balance, but it would require several years to allow for the total recovery of the peatland due to Sphagnum recolonisation. Nevertheless, Price et al. (2003) explored the water table drawdown phenomena around drainage ditches through a simple unpublished model relating the rate of drawdown to the conductivity $(K)$ and specific yield $(S y)$ of peat, and showed that water table drawdown by drainage ditches was relatively modest, based on the values of $K$ and $S y$ for their peat system. Similar models have been used, such as DITCH, to explore the possibility of re-flooding wetland sites in the UK by managing ditch water levels. However, limitations were found in the approach due to vertical and horizontal heterogeneities in $K$ and $S y$, which do not necessarily transcribe to successful management of water levels in the centre of drained fields (Armstrong, 2000; Gavin, 2003).

Specific responses of wetlands to technical rehabilitation by channel control structures has received very little attention; however, Debano and Hansen (1989) and Schmidt and Debano
(1990) showed through various catchment studies in the southwestern United States that gully check dams were not only able to trap sediment but also raise water tables in desiccated riparian channel surroundings, with the effect of re-establishing lost riparian vegetation. Meanwhile, in South Africa, Ellery and Kotze (2008) report the successful restoration to above-ground water levels in the Killarney wetland in KwaZulu-Natal; this followed the installation of rehabilitation weirs to block erosion gullies draining the wetland, noted by the hugely variable water table levels at these junctures. In a similar study, Ellery and Kotze (2008) demonstrated at the Dartmoor Vlei, also in KwaZulu-Natal, the propensity for wetland rehabilitation via weir type structures to control for groundwater rechargedischarge fluctuations maintaining a wetland's hydrology. Since the height of a structures spillway level would, if above the wetland's surface topography, facilitate vertical recharge from the gully channel into the wetland, or, if below the surface drainage from the wetland, would continue into the gully channel.

This manuscript presents findings from a monitoring study characterising the hydrological response to technical rehabilitation of one particular wetland which had been severely eroded by gullies (dongas). This is necessary since erosion, consequent wetland desiccation, and loss of ecosystem services are considerable problems that need to remedied in the Sand River catchment, as these wetlands support the local population through being a subsistence cultivation resource.

\section{Methods}

The Manalana catchment (Figs. 1a and 1b) comprises denselypopulated rural housing with wetland and dryland cropping areas, as well as a dense network of roads and pathways. The dominant geology is granite, and, from field observation, appears to have dolerite dykes running parallel to the longitudinal orientation of the catchment. The granite is therefore the key source of the sand sediments, and, whilst the dolerites will contribute to the occurrence of clays in the catchment, it is also postulated that the granites are the dominant source of clay particles through illuviation to the valley bottom (Riddell et al., 2010). The catchment is also characterised by large erosion scars on its hillsides in addition to those erosion gullies within the wetland itself. The catchment comprises heavily-grazed Legogote sour bushveld grassland (Mucina and Rutherford, 2006) and thicket. The natural wetland vegetation is dominated by Phragmites mauritianus in areas that are not being cultivated and commonly re-colonises abandoned cultivated plots fairly rapidly. The wetland itself is predominantly an unchannelled valley bottom wetland, although a distinct channel is now observed downstream of the central gully head. The wetland itself is generally of a coarse sand matrix, with lower clay content than the surrounding interfluves, although this sand overlies a deep clay horizon below $\sim 2 \mathrm{~m}$ deep. The mean annual precipitation for the catchment has been derived from the nearest long-term dataset, at the Wales rain gauge (19042000) some $2.3 \mathrm{~km}$ away, at $1075 \mathrm{~mm} \cdot \mathrm{a}^{-1}$, which is strongly seasonal, falling mainly between October and March (hence hydrological years, HY, run October-September).

The rehabilitation of the wetlands in the Manalana subcatchment (Fig. 2a) adjacent to the village of Motlamogatsane (formerly Craigieburn) included the installation of an impervious buttress weir (including a $2 \mathrm{~m}$ keyed-in heel at the gully floor plus $3 \mathrm{~m}$ freeboard to the spillway) and a pervious gabion dam (30 m wide, with $5.3 \mathrm{~m}$ deep spillway including $3.3 \mathrm{~m}$ of 


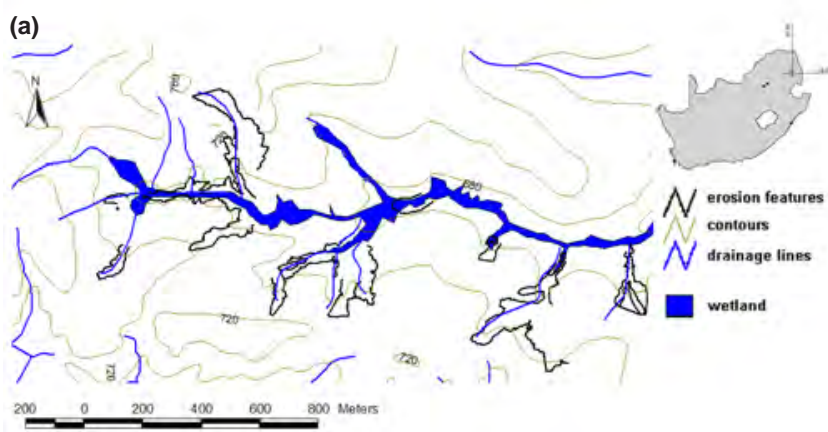

(b) Drakensberg Escarpment

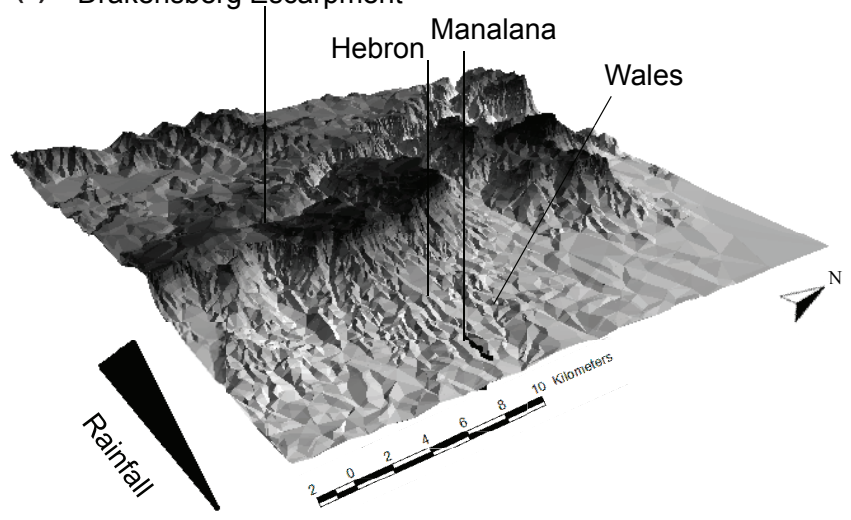

Figure 1

The Manalana sub-catchment of the Sand River and its position within South Africa (a), and its location in proximity to the northern

Drakensberg Escarpment and rainfall gauging stations (b)

freeboard) during the latter half of 2006, in the western and central gully head in Fig. 2a, respectively. The 2 stages of installation of the buttress weir are discussed in the results section.

Hydrological monitoring of the wetland catchment was undertaken with a network of groundwater piezometers and soil moisture tensiometers with up to 3 of each installed at various depths. This was initiated at the onset of the rains in October 2005; the location of those monitoring stations relevant to this study are displayed in Fig. 2a. The piezometer plastic tubing (53 $\mathrm{mm}$ inside diameter) had a $300 \mathrm{~mm}$ slotted interface with the wetland substrate at their installation depths, in which $1 \mathrm{~mm}$ openings were spaced every $6 \mathrm{~mm}$ (Fig. 2b). The annulus between the piezometer tube and augured hole was screened with $10 \mathrm{~mm}$ of coarse sand and then the annulus was backfilled with the original wetland substrate.

Piezometers were regularly dip-read and in some cases automated with differential pressure transducers. The automated piezometers were recorded in accordance with soil moisture tensiometers on a 12-min time step using a University of KwaZulu-Natal (SBEEH-UKZN) and Hobo ${ }^{\circledR}$ timing board and logger system. The use of the Electrical Resistivity Tomography (ERT) technique was used to delineate subsurface geomorphic features, using an ABEM ${ }^{\mathrm{TM}}$ SAS1000 Terrameter. This geophysical technique determines the electrical resistivity distributions of a material and is sensitive to changes in porosity and water content. This is a useful tool in environmental studies to observe spatial variations in lithology and sediments. An analysis of the Manalana catchments geophysical characteristics is detailed in Riddell et al. (2010).

Hydraulic conductivities of the matrix in which the piezometers were installed were estimated using slug tests, which
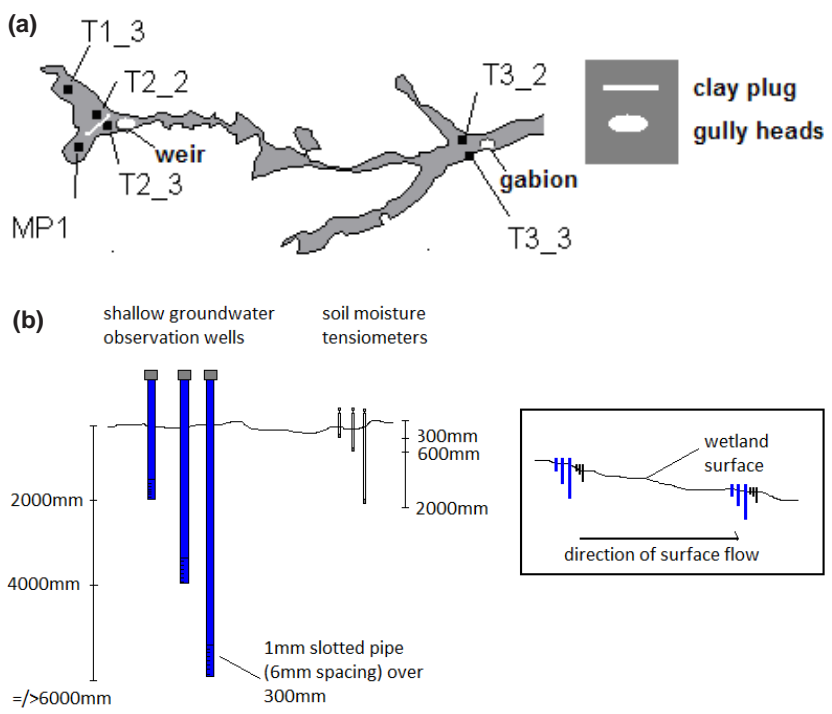

Figure 2

Location of monitoring stations at the headward end of the Manalana wetland (a), and typical piezometer well nest installation (b)

requires the near instantaneous removal of a known volume of water using a $2 \ell$ bailer from the piezometer well and measurement of the water table recovery over time. Estimates of conductivity were determined using the method of Bouwer and Rice (1976) in the form:

$$
K=\frac{r_{c}^{2} \ln \left(R_{e} / r_{w}\right)}{2 L} \frac{1}{t} \ln \frac{y_{0}}{y_{t}}
$$

where:

$K$ is the hydraulic conductivity of the aquifer;

$L$ is the height of the open screen portion of the piezometer at its interface with the wetland matrix;

$y$ is the vertical distance between water level in the piezometer at any time $t$ and that within the aquifer at equilibrium at time 0 , where $y$ can be at any depth below the surface at the time of measurement;

$R_{e}$ is the effective radius over which $y$ is dissipated, estimated using known values of piezometer depth $(H)$ and depth to the base of an unconfined aquifer $(D$, assumed to be $15000 \mathrm{~mm}$ here) and empirical look-up tables for dimensionless coefficients describing the geometry of the aquifer (See Bouwer and Rice (1976) for further explanation);

$r_{w}$ is the horizontal radius between the centre of the piezometer and the aquifer (plus piezometer casing and screening material);

$r_{c}$ is the inside radius of each of the piezometer casings.

\section{Results}

Collection of rainfall data within the Manalana catchment itself commenced at the start of October 2005, and allows for examination of inter-annual differences in rainfall regime over the study period (Fig. 3). It is quite apparent that HY2005 and HY2008 were relatively wet, and characterised by intense rainfall events as noted by the sharp increases in accumulative precipitation. Meanwhile HY2006 and HY2007 were relatively dry with approximately a third less volume of rainfall than HY2005 and HY2008. 


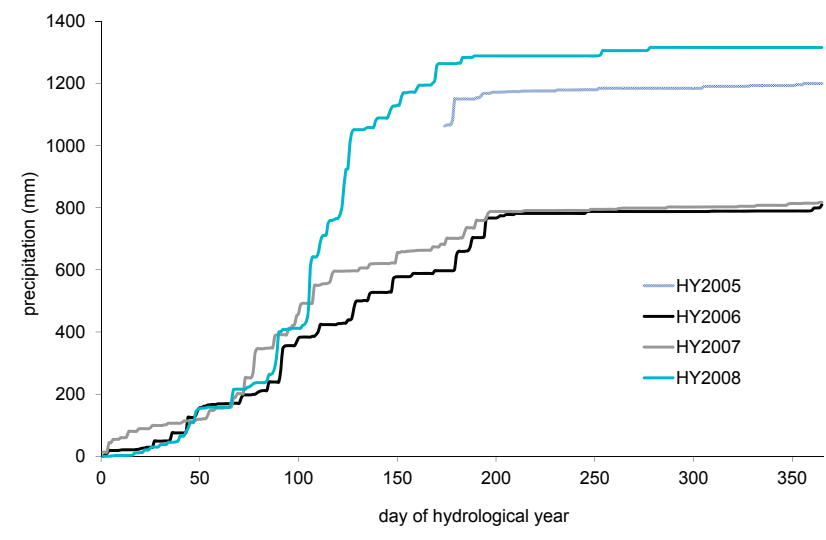

Figure 3

Cumulative rainfall plot for 4 hydrological years of monitoring (HY2005 estimated from on-site manual rain-gauge, following Day 174 automated data supplemented the record)

\section{Initial hydrodynamic behaviour}

The initial observation of the wetland's hydrodynamics during HY2005 came soon after the installation of piezometers at different levels in the wetland substrate and shortly after the onset of heavy rains in early December 2005. Figure 4 displays the piezometric heads as observed in 3 piezometers at location T2_2 between October 2005 and April 2006. After the installation of the 3 piezometers, shallow groundwater levels declined during early October in the $4000 \mathrm{~mm}$ piezometer, whilst the deeper $6000 \mathrm{~mm}$ and shallow $2000 \mathrm{~mm}$ piezometers remained dry. Thereafter there was a steady recharge leading to elevated piezometric head reflected in the $4000 \mathrm{~mm}$ piezometer through to March 2006. Meanwhile, piezometric heads appeared in the remaining piezometers in early January 2006 after significant precipitation events, and these were maintained throughout the rest of the rain season. Three distinct phenomena were therefore highlighted by this observation: First, the wetland seems to display piezometric head stratification, whereby possible shallow seasonal water tables overlay lower permeability horizons in the subsurface. These in turn overlay deeper recharging water tables. The cause of this phenomenon was revealed during soil characterizations in the winter months of 2006. A vertical series of clay horizons were identified in the wetland profiles, forming clay aquitards amongst the coarse sandy matrix dominating the wetland (Fig. 5). Second, the wetland also displays an upward recharging effect within deeper piezometers, since the piezometric head observed in the $4000 \mathrm{~mm}$ piezometer exceeds the elevation of the piezometric head in the $2000 \mathrm{~mm}$ piezometer during March 2006, suggesting that it exists within a (semi-) confined aquifer system and is subject to artesian pressures. Finally, it appears that a threshold condition is required to recharge a deeper groundwater store, as noted by the appearance of a piezometric head in the $6000 \mathrm{~mm}$ piezometer following a rapid elevation of the piezometric head in the $4000 \mathrm{~mm}$ piezometer in early January 2006 (the discontinuity in data for the $4000 \mathrm{~mm}$ piezometer is due to the exceedance of the sensor range), either from the confined aquifer above or from some other mechanism in the catchment.
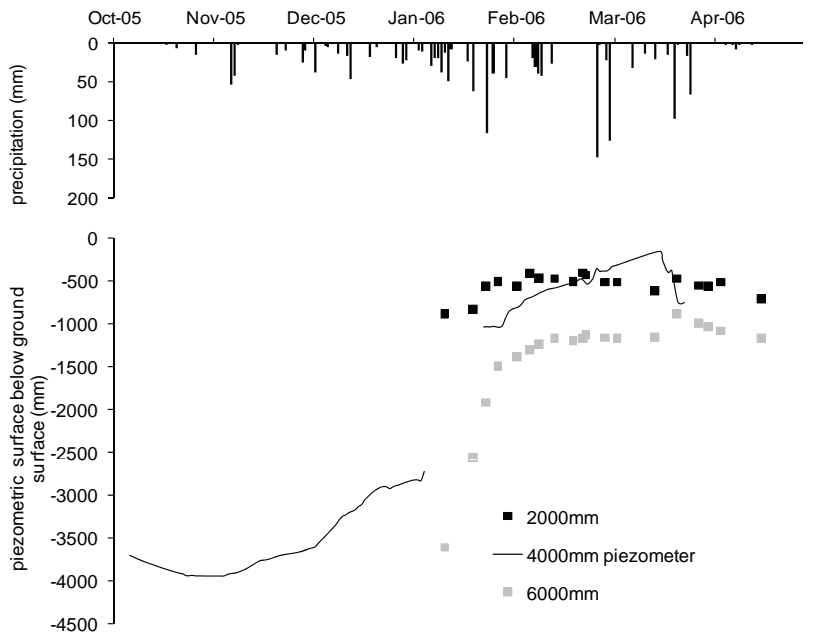

Figure 4

Piezometric heads at T2_2 during HY2005

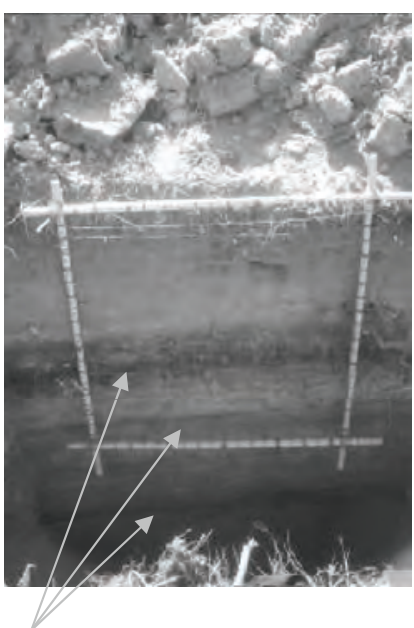

clay layers (aquitards)

Figure 5

Clay aquitards identified in the wetland matrix during soil characterisation

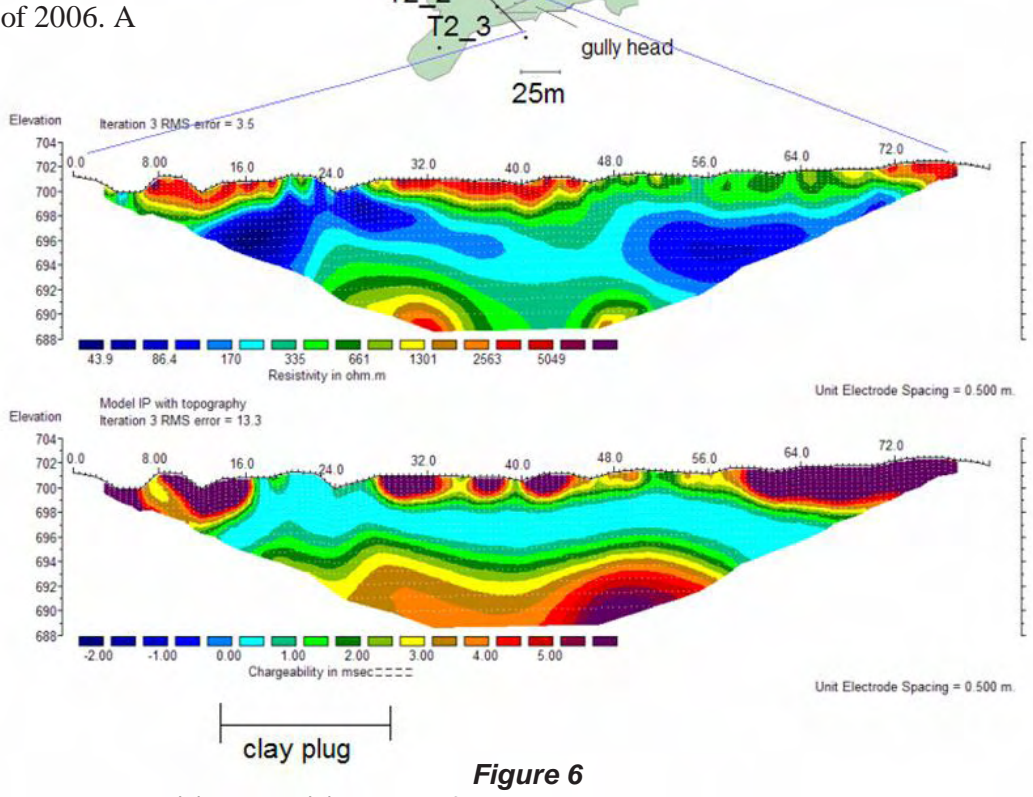

ERT (a) and IP (b) survey of a longitudinal transect through stations T2_2 and T2_3 (August, 2008) 


\section{Geophysical characterisations}

In addition to the lateral clay deposits in the wetland, geomorphologists (Pollard et al., 2005) prior to rehabilitation postulated that moisture is retained within this sandy and rather hydraulically conductive wetland substrate by zones of finer sediment (vertical clay subterranean barriers) termed 'clay plugs'. This has been examined over the course of the study, and Fig. 6 displays examination of the clay plug that was first identified through geophysical analysis in 2006 (Riddell et al., 2007); here we present more detailed data from 2008. The use of the geophysical technique 2-dimensional electrical resistivity (ERT) and induced polarisation (IP) identified one such clay plug that was threatened by any further advance upstream of the erosion gully (the true characterisation and ground-truthing of this geomorphic feature is described in a parallel manuscript by Riddell et al., 2010). Here zones of low resistivity material (0-100 ohms) correspond to the resistance range of clays in the absence of groundwater, similarly the high chargeability bands (chargeability time decreases with increasing capacitance) in the lower diagram correspond to the capacitance range of fine clays. As noted during the initial year of monitoring the hydrodynamic behaviour of the wetland was markedly different upstream and downstream of this clay plug (Riddell et al., 2007). This is demonstrated in Fig. 7 via the apparent large fluctuations seen in the shallow phreatic surfaces at T2 3 which contrast strongly with the lower amplitude fluctuations in the corresponding piezometers further upstream (T1_3 and T2_2). This suggests a hydraulic drawdown through free drainage within the vicinity of T2_3 and/or a buffering effect, such as by a clay plug, somewhere between T2_3 and T2_2 (the clay-plug is hypothetically shown in Fig. 2). Notable in Fig. 6 is the distinct horizontal band of high chargeability material along the length of transect between 694-697 m a.m.s.1., a significant clay aquitard decoupling surface materials from deeper materials.

Figure 8 displays a longitudinal ERT cross-section of the erosion gully and the position of the installed buttress weir; the descent into the gully occurs at chainage $-35 \mathrm{~m}$ along the ERT transect. Using the apparent resistivity ranges for earth materials of Todd (1990) and Sharma (2008), approximate resistivity values range between $10^{0}-10^{2} \mathrm{ohm} \cdot \mathrm{m}, 10^{1}-10^{3}$ $\mathrm{ohm} \cdot \mathrm{m}$ and $10^{0}-10^{2} \mathrm{ohm} \cdot \mathrm{m}$ for clay, sand and saprolitic materials, respectively. Firstly, one observes a low resistance material (blue) to the left of the image. This corresponds to clay materials as just described, whilst the materials $>100$ ohms correspond to sands as well as felsic saprolitic intrusions, which form the vertical bands of high-resistivity material at $-14 \mathrm{~m}$ and $27 \mathrm{~m}$. This effectively reveals that the wetland, certainly at the location revealed in the ERT image, overlies a series of semi-confined aquifers at depth (i.e. the disjointed blue zones of Fig. 8). Noteworthy, is the positioning of the buttress weir (adjacent to the headcut) in close proximity to the intruding bedrock material.

\section{Hydrodynamic response to rehabilitation}

Table 1 summarises the accumulative rainfall from the beginning of the hydrological year to dates at which various aspects of the buttress weir installation were implemented during HY2006 and their equivalent dates in preceding and proceeding hydrological years. One notes the relative similarity in rainfall leading up to the completion of the buttress weir heel at Day 81 for HY2005, 2006 and 2008, and large difference in cumulative rainfall at the closure of the weir's spillway between HY2005, 2008 and HY2006, 2007.

Figure 9a displays the longitudinal topography of the Manalana wetland with the section of down-cutting by the erosion gully and the relative position of the buttress weir across the erosion gully and keyed in to $2 \mathrm{~m}$ below the gully floor. The aim of this structure was first to prevent any further sediment movement out of the wetland by way of the gully channel, by creating an area of ponded back-water behind it. A secondary effect could possibly lead to a buffering of the seasonal hydraulic drawdown adjacent to the erosion gully. Furthermore, it may then facilitate vertical recharge to the deeper groundwater store, and as such it is proposed to lead to a restoration of the hydrodynamic regime of the wetland. The initial season

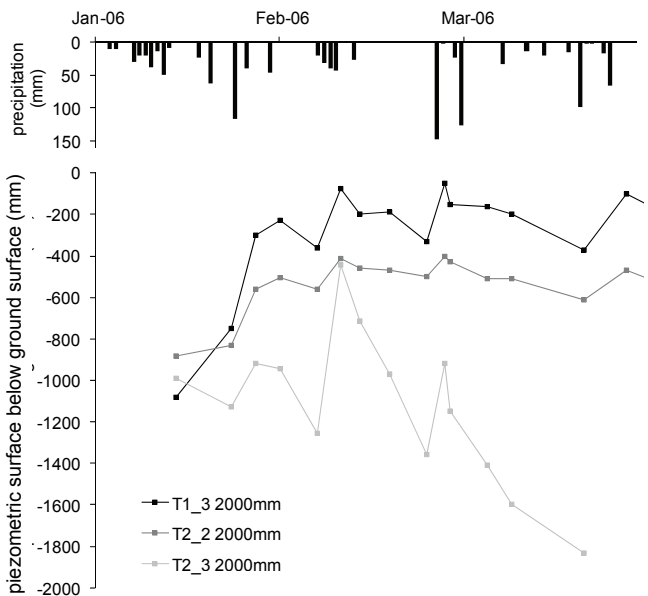

Figure 7

Shallow piezometric head behaviours, January to April during HY2005

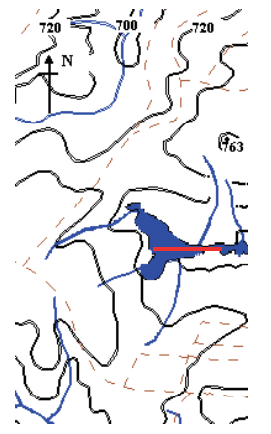

Approx. orientation of ERT transect

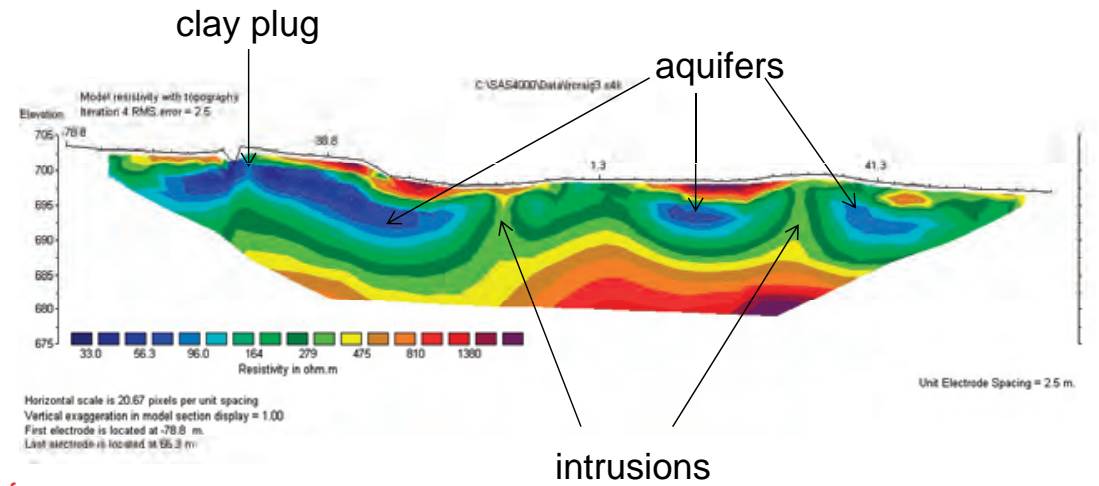

intrusions
Figure 8

ERT longitudinal section through the erosion gully

(May 2005) 


\begin{tabular}{|c|c|c|c|c|c|c|}
\hline \multicolumn{7}{|c|}{$\begin{array}{l}\text { Table } 1 \\
\begin{array}{c}\text { Accumulative rainfall }(\mathrm{mm}) \text { in the Manalana catchment for stages of construction of the buttress weir } \\
\text { by equivalent day of year for the } 4 \text { hydrological years of monitoring, which each start at } 1 \text { October } \\
\text { ('year in which structure was actually put in place) }\end{array}\end{array}$} \\
\hline & & Day of year & HY2005 & HY2006* & HY2007 & HY2008 \\
\hline Heel start & 05-Dec & 66 & 162.8 & 169.3 & 159.4 & 175.5 \\
\hline Heel complete & 20-Dec & 81 & 222.8 & 210.6 & 345.8 & 237.1 \\
\hline Slab & 05-Feb & 128 & 569.0 & 475.5 & 596.6 & 1050.5 \\
\hline Spillway shut & 23-Mar & 174 & 1063.0 & 597.0 & 682.5 & 1263.4 \\
\hline
\end{tabular}

observations for HY2005 effectively provide evidence for a degraded hydrological state; observations in subsequent years following rehabilitation would allow for the assessment of hydrodynamic response to technical rehabilitation.

The HY2006 season represents data during and immediately following rehabilitation (which was initiated in November 2006). During the HY2007 season erosion processes undermined the structure and prevented the weir from buffering any wetland discharges at the surface and near sub-surface. The HY2008 season represents data where the erosion problems had been remedied and the weir was doing its job as intended, in geomorphologic terms, for the duration. Figure $9 \mathrm{~b}$ displays the initial observed effect of this rehabilitation structure, in which, again, the longitudinal topography is displayed along with the maximal piezometric head elevations (or minimum depths) experienced during the 4 HY2005-08 wet seasons. It is important to note here that the HY2006 season was considerably drier than the previous year (recalling Fig. 3), and during this same year, where the rehabilitation was implemented, the piezometric head rose to a greater elevation than the wetter HY2005. Also in Fig. 9b, the perched (seasonal) piezometric head did not rise as close to the surface in the second year after rehabilitation where erosion had undermined the structure (HY2007). Additionally, in the latest season following successful intervention (HY2008), the perched piezometric head had a similar elevation as the HY2005 season and adjacent to the weir it was dominantly near the ground surface.

Closer examination of the initial response of the wetland hydrodynamics to the buttress weir installation are revealed in Figs. 10 and 11. In both cases the phases of construction are displayed, whereby the $2 \mathrm{~m}$ heel was constructed first, followed by the weir itself with key and wing walls. The most noticeable aspect in Fig. 10 is the steady rise and fall of the seasonal piezometric heads in the pre-rehabilitation year in response to precipitation inputs. Meanwhile, following the construction of the weir and in particular its full completion, the weir had appeared to create a rapid seasonal phreatic surface rise which is observed all the way up the wetland up to station T1_3 in response to some 50-60 mm events towards the end of March 2007. Furthermore, the sequence of head differences is a reversal of the previous year's hydrodynamic behaviour in the shallow subsurface (within $2000 \mathrm{~mm}$ ). For instance, the piezometric head at T2_3 is shallower than at T1_3 in the HY2005 hydrological year. More significant, however, is the permanency of these 2 piezometric heads. The T2_3 piezometric head is short-lived in HY2005, observed only between January and April 2006, while at T1_3 it resides for a much longer period between December 2005 and May 2006. Since T2_3 is further downstream it would be expected that the phreatic surface would exist for longer due to a greater contributing area of inflow from upstream; however, what occurs here is a hydraulic drawdown of the seasonal water adjacent to the active gully head, effectively a 'leakage’ from the system. Meanwhile, the
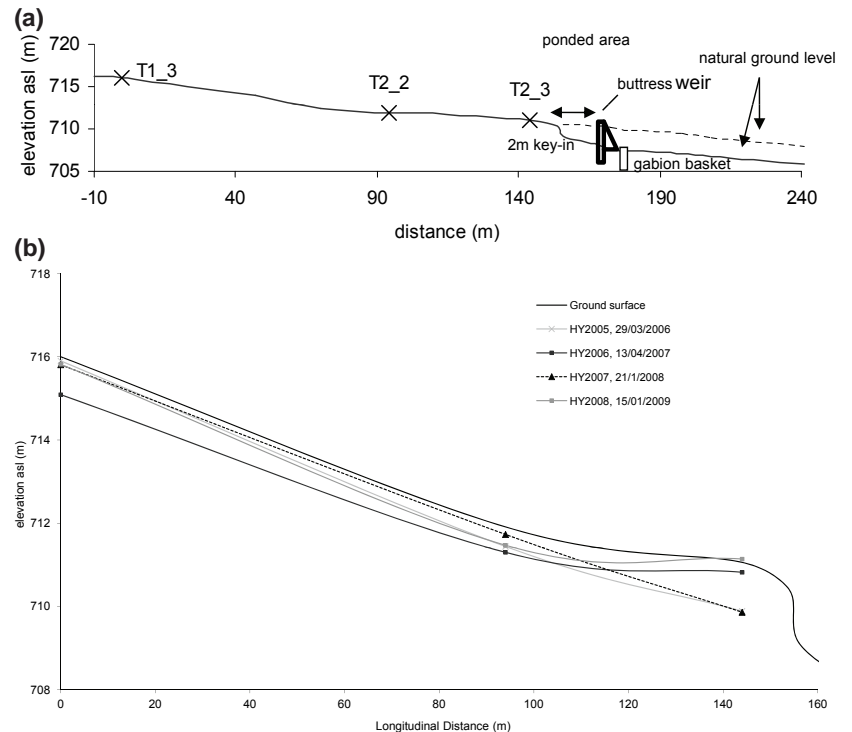

Figure 9

Longitudinal topography of the Manalana wetland (a), maximum seasonal (perched) water table elevations (b)

expected order has been restored in the HY2006 season where the T2_3 piezometric head exists for longer and in closer proximity to the wetland surface than at T1_3 due to the 'plugging' of the system at the weir.

Figure 11 reveals the process responses of the wetland at T2_3 to the new buttress weir installed during HY2006. Firstly, there is a sharp rise in the piezometric head in the deepest piezometer $(7000 \mathrm{~mm})$ and appearance of piezometric heads in the shallower piezometers (2 000 and $4000 \mathrm{~mm}$ ) after the construction of the heel. The fact that the deeper piezometer expresses a head similar to the shallower piezometers suggests the upward (artesian) movement of water at that region, possibly as a result of a (semi-) confining aquiclude of subsurface material between the $4000 \mathrm{~mm}$ and $7000 \mathrm{~mm}$ piezometers. This is similar to that observed at T2_2 in Fig. 4 for HY2005. Thereafter a downward movement of water occurs for the remainder of January 2007 due to lower heads expressed at each successively deeper piezometer. The piezometric head in both the $2000 \mathrm{~mm}$ and $4000 \mathrm{~mm}$ piezometers had disappeared by the end of February 2007 and then reappeared following large rainfall events at the end of March, in which the 2000 $\mathrm{mm}$ piezometer experiences a very rapid rise in head followed by a decline. Meanwhile the $4000 \mathrm{~mm}$ piezometer has a steady reappearance and recharge in head. These are then followed by a much slower increase in piezometric head in the 7000 mm piezometer throughout April 2007, although the artesian pressures here are less pronounced than earlier in the season. The behaviours of the 2 shallow piezometers compared to the deepest at T2_3 suggest that vertical movement of water is 


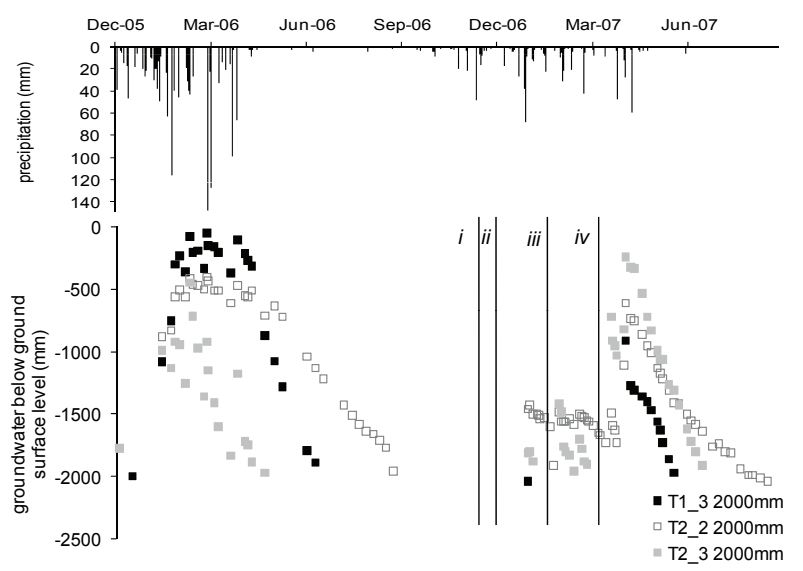

Figure 10

Initial responses in the piezometers to placement of heel and closure of structure (' commence heel installation, "finish heel,

iii lay buttress weir slab, iv close spillway)
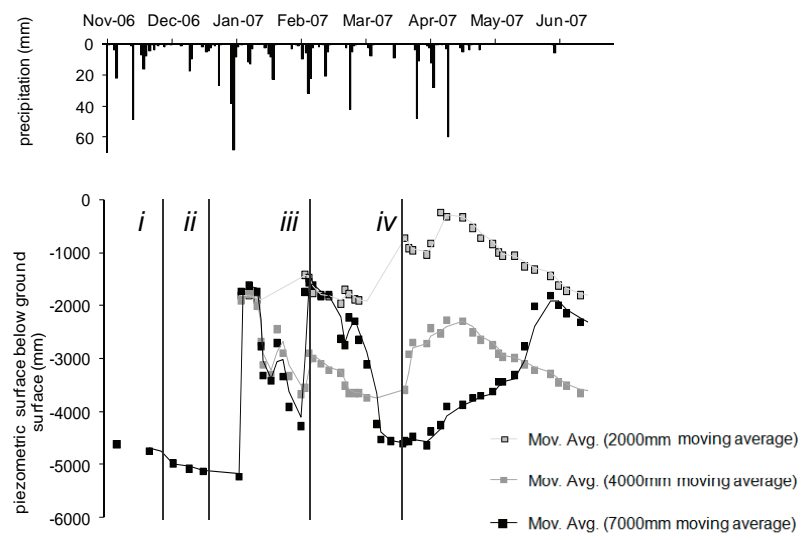

Figure 11

Initial response to placing of heel and closure of structure for the 3 piezometers at T2_3 (' commence heel installation, "inish heel, iii lay buttress weir slab, iv close spillway)

not totally disconnected from depths $>4000 \mathrm{~mm}$, but that the wetland operates largely as an unconfined aquifer system in the shallow sub-surface overlying semi-confined aquifers at depth.

\section{Hydrodynamics over 4 years}

The piezometric head distributions for all of the observation piezometers at the headward end of the Manalana wetland over the 4 years of monitoring are displayed in Fig. 12. Examination of the behaviours at this temporal scale reveals some interesting contrasts amongst different locations in the wetland. For the most headward responses at T1_3 (Fig. 12a), the elevated piezometric head is short-lived and is unconfined, at least up to $4000 \mathrm{~mm}$, as both piezometers show similar elevations. Interestingly the piezometric head here reaches a winter (dry period) stable depth of around $2300 \mathrm{~mm}$ below the ground surface in most years, except during the dry period of 2008 when there was some considerable drawdown of the piezometric head here to around $-2900 \mathrm{~mm}$. This likely represents the effect of consecutive dry periods (i.e. preceding 2 seasons were relatively dry). Furthermore, this region has a very rapid response to precipitation inputs as the piezometric head elevates rapidly following the onset of rains. Within the core of the wetland at T2_2 (Fig. 12b), as discussed previously, the groundwater compartments are somewhat disconnected as is evident by

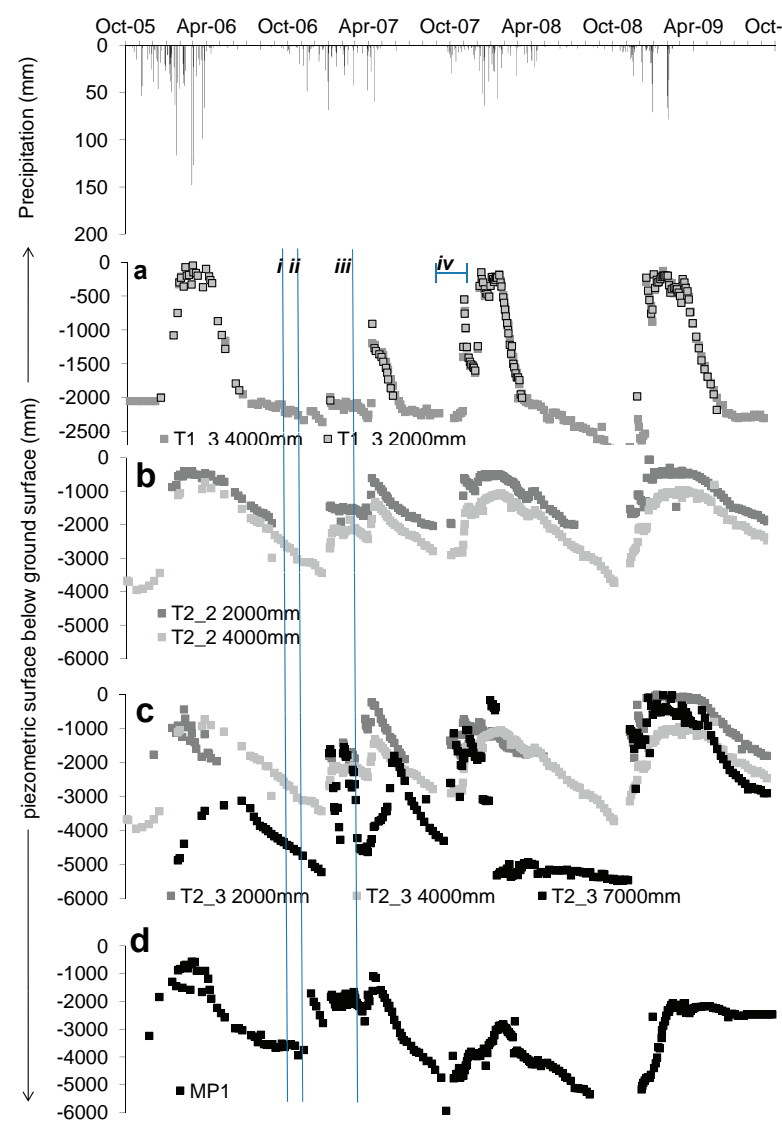

Figure 12

Piezometric head distribution over 4 monitoring seasons at all locations above the buttress weir (' commence heel installation, "i finish heel, iii close spillway, iv erosion around weir)

their different elevations in piezometric head. Here there is a sharp response in all piezometers to the installation of the weir, particularly to the large event preceding this, in March 2007. Meanwhile during the following seasons, HY2007 and HY2008, a change in the hydrodynamic behaviour in the 6000 $\mathrm{mm}$ piezometer is noted. Here the winter recession is observed during 2007, as in previous seasons; however, there is no recovery of this in the subsequent seasons. Despite this, the piezometric heads observed in the shallower piezometers continue to respond as they had previously, and in the winter of 2008 the piezometric surface effectively dropped below the 4000 $\mathrm{mm}$ depth which had not occurred in previous seasons. Also of interest is the closeness of responses in the $2000 \mathrm{~mm}$ and $4000 \mathrm{~mm}$ piezometers at this location. Observations at T2_3 (Fig. 12c) reveal the extent to which the installation of the weir induces a rapid change in the hydrodynamics of the wetland at this location. During the first season of monitoring, there was a very low head expressed deep within the wetland substrate (7 $000 \mathrm{~mm}$ piezometer), whilst the shallow $2000 \mathrm{~mm}$ and $4000 \mathrm{~mm}$ piezometers revealed their seasonal nature and possible connectivity, as both displayed piezometric surfaces at similar elevations below the ground surface. Subsequently, following the initiation of rehabilitation, artesian pressures are reflected by the $7000 \mathrm{~mm}$ piezometer for the remainder of the period (except for the winter of 2008, when water was extracted from this piezometer for analysis), whilst only in HY2008 is there a return to the similarity of piezometric heads seen in the $2000 \mathrm{~mm}$ and $4000 \mathrm{~mm}$ piezometers. The preceding 2 
seasons were, despite similar fluctuations, of marked difference in terms of their expressed piezometric heads, such that both $2000 \mathrm{~mm}$ and $4000 \mathrm{~mm}$ piezometric heads show parity in HY2007. This is possibly a reflection of saturation variabilities arising from large differences in seasonal rainfall. Artesian pressures were again seen in the HY2008 season in the 7000 $\mathrm{mm}$ piezometer following an extraction of water from this well during winter. At MP1 the seasonal trends can quite clearly be seen (Fig. 12d), with a steady decrease in the piezometric head from the wet HY2005 season to the dry HY2007 season. However, even in the wet HY2008 season, and following the rehabilitation, the maximal expressions of head do not reach the same shallow depths as were observed during the HY2005.

Figure 13 shows the expressed piezometric heads further downstream, adjacent to the other rehabilitation site where a large gabion dam was installed during late winter (June-September) 2006. In the piezometer at T3_2 which was installed to a depth of $2000 \mathrm{~mm}$ one observes an initial recovery of the shallow groundwater following its installation; this is repeated in early 2008 when water was abstracted from this piezometer. Particularly noteworthy is the extremely slow recovery of the head in the piezometer following abstraction. Clearly this is not due to rainfall since the expressed piezometric head at this location remains relatively stable throughout the entire monitoring period. Hence a material exists here with extremely low hydraulic conductivity, as explained by the very fine clays observed throughout the profile. Furthermore the piezometric head seems to be relatively stable here even during the dry season, with only a slight decline of some $200 \mathrm{~mm}$ during the dry winter of 2007. Meanwhile T3_3, also installed to $2000 \mathrm{~mm}$ and in a slightly upslope position relative to T3_2, again shows a relatively continuous piezometric surface, except for flashy periods during mid-summer coinciding with large rain events. From personal observation this site sits adjacent to a hillslope seep that feeds the wetland, through rapid lateral hillslope transfer (Riddell, 2011), which was not apparent during the installation. Both sites are located at a position downstream that receives perennial water, whereas the upstream sites are very much in a seasonal zone.

\section{Hydraulic conductivity}

$K$ was determined for each of the piezometer wells upstream of the buttress weir; however, since the conductivities in the majority of piezometers, and in particular those deeper than $2000 \mathrm{~mm}$, were extremely low, repeated measurements were not undertaken. Hence, the estimates derived are for single piezometer recovery readings where the Bouwer and Rice (1976) method was applied to the straight line portions of the recovery curve. Figure 14 displays the final estimates for these piezometers (albeit without T3_3 since the phreatic surface was too low - such that a bailer was inadequate to remove a known volume of water) and it is quite apparent that the piezometers in the shallowest substrate have the highest conductivities, with the most headward piezometer at T1_3 having the greatest conductivity of all, whilst the shallow piezometer at T2_3 is in a more conductive substrate than the $2000 \mathrm{~mm}$ piezometer at T2_2. The exception is, of course, further downstream at T3_2, where even the shallow material has extremely low conductivity. There is also a trend that may be observed within this plot, in that the conductivity of the wetland substrate decreases considerably with depth to 4000 $\mathrm{mm}$, after which it maintains a very low $K$ of between 0.01 and $0.0001 \mathrm{~mm} / \mathrm{h}$.

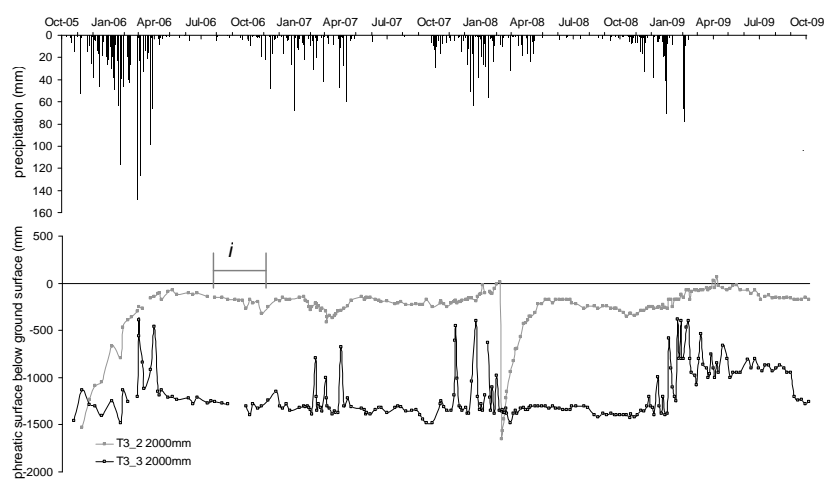

Figure 13

Piezometric head distributions over 4 monitoring seasons at the 2 sites adjacent to the gabion dam ('installation and completion of the gabion dam)

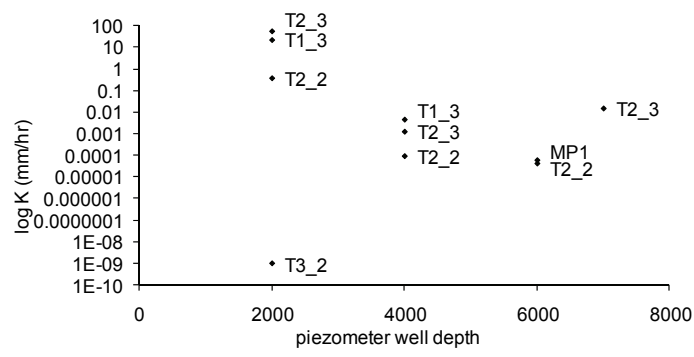

Figure 14

$K$ estimates for piezometers within the Manalana wetland

\section{Hydraulic gradients}

Examination of the hydraulic gradients (i) observed between piezometers at T2_3, in Fig. 15, reveals how the hydraulics of the wetland switched quite markedly following the installation of the weir during HY2006, and in particular during the latest season, HY2008, when the structure was fully functional. Noticeable from Fig. 15 is that $i$ between the $2000 \mathrm{~mm}$ and $4000 \mathrm{~mm}$ well was virtually zero and therefore largely static during the first year of monitoring, whilst a positive gradient existed between 2 $000 \mathrm{~mm}$ and $7000 \mathrm{~mm}$, as well as between the $4000 \mathrm{~mm}$ and 7 $000 \mathrm{~mm}$ piezometers, implying vertical recharge from the shallow layers above. However, in the following 2 seasons, HY2005 and HY2006, $i$ increased between the $2000 \mathrm{~mm}$ and $4000 \mathrm{~mm}$ wells and $i$ between the $4000 \mathrm{~mm}$ and $7000 \mathrm{~mm}$ wells reduced and became negative at the height of the rains. Most striking is the latter part of the season HY2008 where $i$ in all instances became homogenised (i.e. no large fluctuations) and there seems to be a discharging effect in the shallower zone; for instance, the positive $i$ which occurred between the $2000 \mathrm{~mm}$ and $4000 \mathrm{~mm}$ piezometer, whilst a persistent negative $i$ existed between the 4 $000 \mathrm{~mm}$ and $7000 \mathrm{~mm}$ piezometer, indicating recharge contributions from elsewhere to the $7000 \mathrm{~mm}$ depth and an upward flux between $7000 \mathrm{~mm}$ and $4000 \mathrm{~mm}$ at the buttress.

The observed $i$ values between the deepest piezometers in the system (Fig. 16) are also noteworthy; although their magnitudes are much lower than those just described, there is a noticeable switching of hydraulic gradients. One may note the gradient of flow from both $6000 \mathrm{~mm}$ piezometers at MP1 and T2_2 to T2_3, during the first season, HY2005. The hydraulic gradient in both cases reduced to close to zero during the winter of 2006, suggesting that a hydraulic head and consequent recharge from elsewhere in the catchment was also diminishing. This phenomenon continued into the following season, HY2006, 


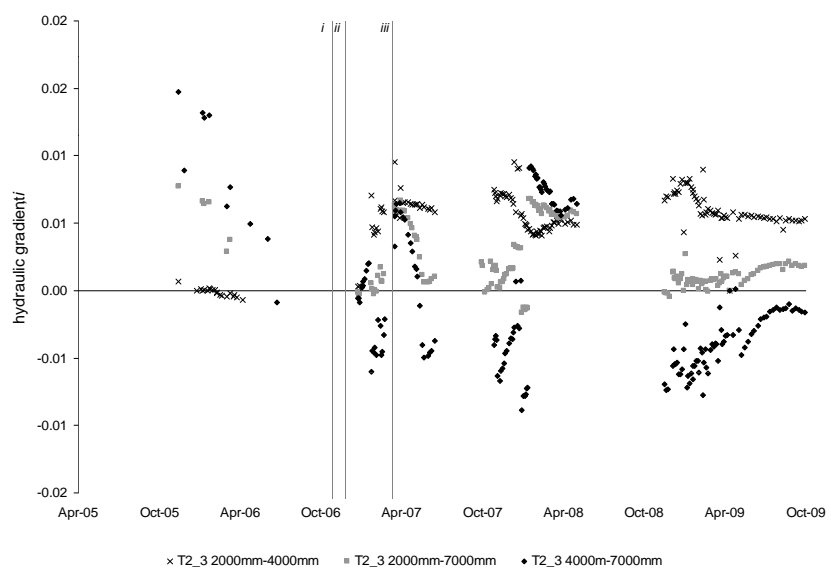

Figure 15

Hydraulic gradients as determined at T2_3 (' commence heel installation, "ii finish heel, iii close spillway)

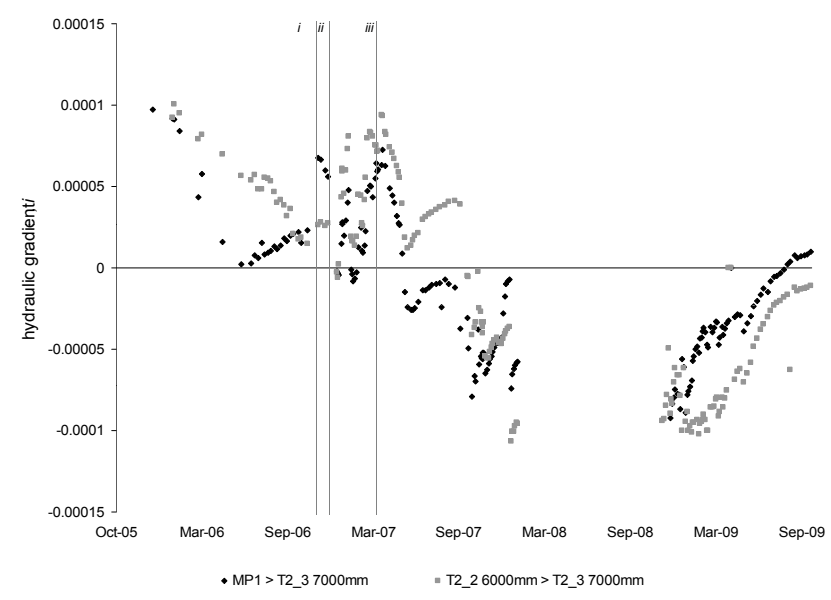

Figure 16

Hydraulic gradients as determined between the deepest Piezometers at MP1, T2_2 and T2_3 (' commence heel installation, "finish heel, "iii close spillway)

until the installation of the weir between December 2006 and March 2007, following which the hydraulic gradient reversed; this was also a noticeably dryer season than the preceding one. For the period between March and September 2008 the data are erroneous due to water abstractions from the piezometer wells, and have therefore been excluded. Finally, in the most recent season, HY2008, the hydraulic gradient remains in the reversed state with piezometric heads at T2_3 apparently greater at T2_3 than at either MP1 or T2_2.

\section{Antecedent and seasonal effects}

Examination of piezometric head behaviour within the Manalana wetland would not be complete without the contextual understanding of conditions within the system at the start of the hydrological year, in addition to those applying to a complete hydrological year before and after the rehabilitation intervention (i.e. where there were no failures or modifications to the structure). Figure 17 displays the piezometric head hydrodynamics at the T2_3 site adjacent to the erosion gully for 2 complete hydrological years with similar cumulative rainfall, HY2005 and HY2008, the former year being that prior to rehabilitation and the latter that in which the rehabilitation structure remained intact. It is quite clear from Fig. 17a that
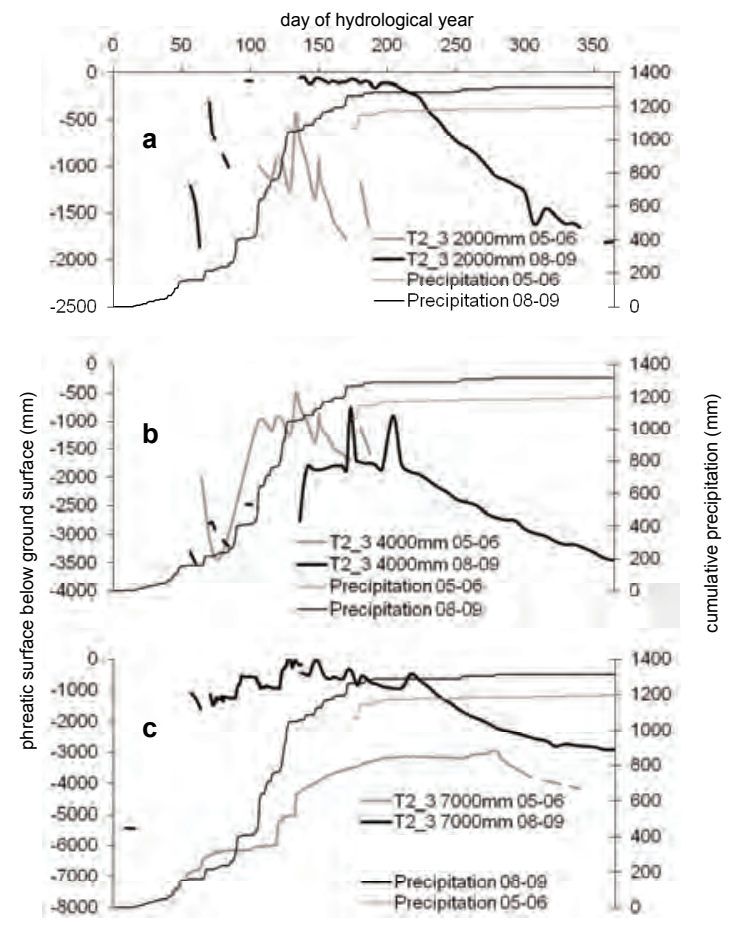

Figure 17

Examination of annual piezometric head responses at T2 3 for years with similar rainfall regimes pre- and post-rehabilitation

the hydrodynamic behaviour within the shallow piezometers of T2_3 during HY2005 was very erratic and short-lived, falling below the $-2000 \mathrm{~mm}$ well depth early on in the dry season, beyond Day 150. Meanwhile, during HY2008 a piezometric head was observed here for short periods early on, up to Day 140 , whereafter it had a relatively stable elevation close to the wetland surface, and, despite a winter drawdown, a piezometric head was still recorded within this piezometer up to the start of the following hydrological year. A similar response is also observed for the piezometric head as recorded in the $4000 \mathrm{~mm}$ piezometer in Fig. 17b, although here a piezometric surface appeared early on during HY2005; however, it had ceased to be present by Day 200, whereas during HY2008 a piezometric surface was again observed throughout the year and never dropped below the $4000 \mathrm{~mm}$ piezometer well. Figure 17c reveals the very different nature of response at depth in the 7 $000 \mathrm{~mm}$ piezometer. Here one sees that the piezometric head during HY2008 appears very suddenly soon after Day 50 and remains largely within $1000 \mathrm{~mm}$ of the wetland surface well into the winter months, past Day 200. By the end of HY2008, a piezometric head is still expressed here above $-3000 \mathrm{~mm}$ depth. This contrasts strongly with HY2005 where the piezometric head in the $7000 \mathrm{~mm}$ well appears to gradually elevate early on during the season, reaching an asymptote at approximately Day 275 before receding once more.

Figure 18a displays the hydrodynamics of the piezometric surface at T2_2 for the $2000 \mathrm{~mm}$ piezometer. Here one observes a short-lived piezometric surface during HY2005, having disappeared well before Day 200, contrasting strongly with an expressed head of greater duration during HY2008 which only falls below the $2000 \mathrm{~mm}$ piezometer at approximately Day 280 . Interestingly, Fig. 18b for the $4000 \mathrm{~mm}$ piezometer shows that the piezometric surfaces at this depth behave with great similarity, with a gradual recharge in elevation early on during both hydrological years. There is also a steady decline into winter 


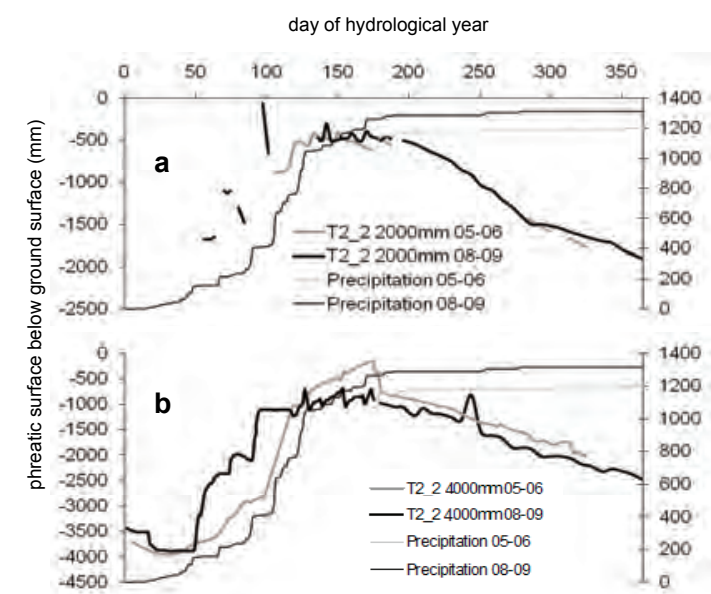

Figure 18

Examination of annual piezometric head responses at T2_2 for years with similar rainfall regimes, pre- and post-rehabilitation

after the mid-summer asymptote, with both maintaining a presence above $-3000 \mathrm{~mm}$ beyond Day 300 .

\section{Discussion}

Initial hydrodynamic behaviours showed that the system has vertical recharge processes and that, at depth, the presence of semi-confined aquifers deeper within the wetland at times yields artesian conditions. Recharge processes occur through the shallow subsurface via direct precipitation and localised infiltrating runoff. However, in deeper regions of the wetland below 4000 $\mathrm{mm}$ water is likely to also be percolating from shallower horizons. Also the behaviour of the piezometric surfaces at these depths suggests another mechanism in the form of recharge to the wetland at a larger scale, from the surrounding catchment or regional water table, for example. Indications for this are the late appearance of a deep piezometric surface at T2_2 during the first year of monitoring and the permanent occurrence of water in the deepest piezometer at T1_3. Furthermore, the artesian forces observed at T2_2 in the $4000 \mathrm{~mm}$ piezometer during this same season suggest that such large-scale recharge processes also occur in shallower regions below $2000 \mathrm{~mm}$. In essence, therefore, the vertical recharge processes suggest coupling to surface waters at shallow depth, whilst this becomes increasingly decoupled with depth in favour of coupling to broader groundwater sources in the catchment. The observations here imply a connection of the wetland to a dual aquifer system, similar to that identified for a dambo wetland system in Zambia (Von der Heyden and New, 2003). Hence a shallow aquifer from the catchment soils and saprolites maintained the shallowest piezometric responses and the deeper and more permanent (perennial) piezometric surface was connected to underlying bedrock or, in this case, perhaps deeper saprolites. These are quite evident in exposed surfaces of deeply eroded areas within the surrounding interfluve. This of course has warranted further investigation using tracer techniques in the case of the Manalana wetland.

The ERT analysis also supports this notion of a shallow surface hydrology decoupled from a system at depth, as the results quite clearly portray a horizontal aquiclude. The $K$ estimates possibly confirm this as we see a slight increase in the conductivity of the wetland material at piezometer depths below 4000 $\mathrm{mm}$, whilst the $4000 \mathrm{~mm}$ material itself has an extremely low hydraulic conductivity. This warrants further assessment of the hydraulic conductivity of this wetland at such depths, using a greater spatial sampling intensity. Whether this aquiclude system would have continued downstream in the same decoupled manner remains uncertain. However, the vertical intrusions observed downstream of the headcut in Fig. 8 suggests that this would not have been the case.

What does this say about the consequent impacts of the rehabilitation structures? Figures 6 and 8 suggest that the actual site selection of a rehabilitation structure and indeed the type of structure will certainly have an influence on the hydrologic regime of a wetland. This could, for instance, be due to introducing foreign materials (rehabilitation) which come into contact with materials that shape the hydrology of the system, such as an impermeable material adjacent to permeable materials, and thus induce preferential flow processes. The proximity of this structure to the vertical intrusion implies a sealing off of the wetland, at the toe of the upstream portion (refer to Figs. 1 and 2a, noting the large erosion gully between the regions monitored), from the stream channel and stream bed that now exist where the wetland has been eroded due to gullying. A deep groundwater discharge zone, which likely seeped further downstream previously, is then able to induce recharge to the wetland from below. This would then explain the artesian phenomena observed at T2_3 following rehabilitation. Moreover this would reiterate the similar artesian phenomena observed at T2_2 prior to rehabilitation.

There is no doubt that the placement of a deep $2 \mathrm{~m}$ heel plus $3 \mathrm{~m}$ freeboard on the buttress weir has had an effect in terms of changing the hydrology of the system from its eroded state, as shown by the shift in hydraulic gradients over the season and stark contrast between HY2005 and HY2008. Whether these hydraulic gradient shifts would have occurred had the structure been placed in an alternate location leads to speculation. However, the precise positioning of rehabilitation structures certainly needs to be considered when rehabilitating large systems in which managing the system for hydrology is deemed important. This should also be considered in catchments where many rehabilitation interventions are likely to take place and in which cumulative hydrological effects are most likely to be felt downstream. As Owen (1995) as well as Preston and Bedford (1988) propose, evaluating the cumulative effects of wetland loss or modification on the landscape and catchment processes should be based on the concept of wetlands with various fluxes contributing to different types of water budget and their altered/unaltered role on stream flow processes. Although the precise role of differing wetland types in the hydrological cycle is still uncertain (e.g. Bullock and Acreman, 2003), the fact that the hydrology of wetland systems undoubtedly changes through erosion processes means that there are certain fundamental requirements for catchment rehabilitation through wetland rehabilitation. In cases such as the Sand River wetlands, where there are a plethora of potential rehabilitation interventions, this necessitates the most appropriate method and precise deployment of the intervention in order to revert to wetland hydrological processes as close to the unaltered state as possible.

Aside from the cumulative effects just discussed, there is also the issue of within-wetland variability. This study has quite clearly shown that different regions, even within this comparatively small system, yield differing hydrodynamic responses to rainfall inputs and throughflows. As Riddell et al. (2010) suggest based on geophysical examination of this wetland's hydro-geomorphology, a unique combination of illuviation of fine materials from the surrounding hillslopes, occurring at zones where the contributing catchment becomes longitudinally constricted, have facilitated the formation of these clay plugs. Crucially, therefore, it is noted through this study that geomorphic controls should 
be explicitly considered; in this instance clay plugs significantly enhance the longevity of the wetland's hydroperiod, without which the wetland would not be able to hold water, certainly not from the wet into the dry season. In the absence of such controls it would be expected, and certainly appears to be the case in other unrehabilitated wetlands in the Sand River catchment, that these headwater systems are showing hydroperiods moving from seasonally inundated to largely ephemeral hydrology, since they appear to show signs of desiccation (see, for example, Pollard et al., 2005).

This intra-wetland hydrological variability adds another layer of complexity to the two, usually exclusive, issues of wise-use and rehabilitation of wetlands, suggesting the moniker 'wise-rehabilitation' for these heavily degraded systems. Dixon (2002) showed a similar scenario in the wetlands of the Illubabor Zone of Ethiopia, which were also used for subsistence agriculture derived from both natural and enforced re-settlement. Here different hydrological 'micro-regions' were also noted to exist within the systems in question, and these had different responses to the impacts of drainage and cultivation. However, Dixon (2002) concludes that, despite the agronomic pressures on these wetlands, for the most part these practices are hydrologically sustainable, and attributed this to indigenous knowledge of these systems. This unfortunately is lacking in the wetlands of the Sand River, where there was no history of wetland cultivation, particularly in this setting, by the resettled population. Nevertheless, this study reveals that sustainable utilisation of these wetlands may be achieved through the careful identification of hydrologically sustainable micro-regions within the Sand River wetlands, married with suitable rehabilitation of degraded regions; however, it may be that the considerable demands on these catchments may negate this.

Nevertheless, guiding principles emerge from the evidence outlined in this paper that can be used for successful rehabilitation of wetlands in the Sand River catchment and possibly elsewhere, and this will be achieved when detailed ground-truthing is carried out prior to any construction of structures. First, observations based on the soil (soil water processes) and geological (obvious controls - bedrock controls, for example) composition of the wetland will allow for the development of some form of conceptual hydrological model of the wetland and the impact that differing types of rehabilitation interventions may have on the conceptual wetland hydrology. In the case presented here it is certainly the presence of layered and plugged clays that control the hydrology in the natural state, and the positioning of bedrock outcrops can play an important role in restoring the hydrodynamics - if the rehabilitation structures are keyed-in to a satisfactory depth to effectively seal the wetland. The type of monitoring discussed here (i.e. piezometer networks and geophysical surveys) can be done at relatively little cost, especially when compared to the significant capital expenditure of installing and maintaining such rehabilitation structures, in order to develop conceptual hydrological models. The merit of this approach has been demonstrated in this study.

Very few studies have addressed the wetland rehabilitation issue directly from a hydrodynamic or hydroperiod perspective, and those that do often entail the use of a reference undisturbed system from which to rate the achievement of the rehabilitation. For instance, Bruland et al. (2003) showed that in the restoration of Carolina Bay wetland in the USA which had previously been drained for agricultural use, filling-in drainage ditches resulted in relatively rapid responses. Furthermore, rehabilitation was deemed successful when the water table elevations were seen to closely resemble the depth and duration of a similar natural wetland. Meanwhile, Dixon and Wood (2003) used cluster analysis to show the clear differences in the hydrodynamics of several comparable wetlands undergoing differing degrees of anthropogenic impact in east Africa. These direct comparisons with 'pristine' systems are obviously the optimal scenario for tracking rehabilitation success; however, this is negated by the extensive alteration of the wetland environments in the Sand River system, where there are very few, if any, truly pristine systems left, compounded by variation in their topographical, geological, climatic and ecological settings. Despite the short-term examination of the wetland's response to rehabilitation in this study, there has clearly been notable positive responses within small regions of the wetland, seemingly controlled by the clay plug and aquicludes. Recalling the artesian pressures observed upstream of the clay plug at T2_2 in the year prior to rehabilitation, in contrast with the hydraulic drawdown of piezometric surfaces in the shallow as well as deep zones at T2_3 downstream of the clay plug, the artesian pressures which were then observed at T2_3 following rehabilitation would suggest a level of success in restoring the system's hydrology, to a certain extent. Of course, longer-term monitoring is required, especially if use can be made of vegetative indicators related to a hydrologic regime; it would be expected that the system will return to hydrophytic vegetation just upstream of the weir.

It is expected that, in the interests of sustainability, wetland cultivation can continue with minimal impact on the wetland's hydrology, given the water budget findings of Riddell (2011). These suggest that the wetlands do not necessarily attenuate flood peaks and augment base flows, but that the former certainly is a function of the prevailing soil moisture deficit in the system and is highly dependent on time in the hydrological season. Nevertheless, agricultural modification of the system will shift the thresholds at which these responses occur. Therefore, in terms of the wetland's ability to sustain agricultural practices, this should follow the proviso that the rehabilitation structures remain in place and sediment in-filling is allowed in the ponded-area behind them. However, key controls on the wetland's hydrology are obviously the distribution of clays within the sandy wetland substrate; in particular, those clays that plug the system, where they still exist, should remain untouched by any anthropogenic/mechanical alteration. In addition, as a horizontal aquiclude controls the vertical distribution of water in the wetland, conservation tillage practices should ideally be incorporated that are allowed to somewhat alter the bulk density of the sandy material but leave these clay horizons intact, since it is these clays which maintain the water retention properties of the wetland system, allowing more prolonged water storage than would occur in their absence.

\section{Conclusion}

This paper has shown that the wetlands of the Sand River headwaters have a variable hydrodynamic behaviour governed by the distribution of clays within an otherwise sandy matrix. These clays form shallow horizontal aquicludes that separate seasonal shallow groundwater from deeper perennial groundwater stores. The underlying of this wetland by a deep aquiclude as well as a vertical clay plug facilitates the artesian pressures in the perennial groundwater. The gullying of the wetlands had quite clearly created a desiccating environment through hydraulic drawdown adjacent to the gully heads, whilst upstream of sub-surface clay plugs the wetland remained hydrologically intact, as revealed by hydraulic gradients within and between shallow groundwater monitoring stations. The 
loss of these plugs, it was shown, could be ameliorated by the installation of rehabilitation control structures, but, as became apparent as the study progressed, the exact positioning of the structures had a considerable influence on the resulting restored hydrodynamic response of the system. This response could be coincidental, highlighting the need for comprehensive ground-truthing of wetland systems when costly rehabilitation measures are planned.

\section{Acknowledgements}

The authors are grateful to the South African Water Research Commission (WRC) and National Research Foundation (NRF) for financial support, and to Working for Wetlands and Eastern Wetland Rehabilitation Ltd, for the rehabilitation of the wetland. The kind assistance of the following people with field work, data processing and interpretation is duly acknowledged: $\mathrm{Mr}$ Ronny Maaboi and Mr Difference Thibela for field assistance, Mr Cobus Pretorius (University of KwaZulu-Natal) and Mr Sean Thornton-Dibb (University of KwaZulu-Natal) for technical assistance. Logistical and administrative support was provided by the Association for Water and Rural Development (AWARD).

\section{References}

ARMSTRONG A (2000) DITCH: A model to simulate field conditions in response to ditch levels managed for environmental aims. Agric. Ecosyst. Environ. 77 179-192.

BOUWER H and RICE RC (1976) A slug test for determining hydraulic conductivity of unconfined aquifers with completely or partially penetrating wells. Water Resour. Res. 12 (3) 423-428.

BRINSON MM (1993) Hydrogeomorphic classification of wetlands. Report WRP-DE-4. U.S. Army Corps of Engineers Waterways Experiment Station, Vicksburg, MS.

BRULAND GL, HANCHEY MF and RICHARDSON CJ (2003) Effects of agriculture and wetland restoration on hydrology, soils, and water quality of a Carolina bay complex. Wetlands Ecol. Manage. 11 141-156.

BULLOCK A and ACREMAN M (2003) The role of wetlands in the hydrological cycle. Hydrol. Earth Syst. Sci. 7 (3) 358-389.

CONWAY D and DIXON AB (2000) The Hydrology of Wetlands in Illubabor Zone. Report 1 for Objective 3. EWRP and University of Huddersfield, Metu and Huddersfield.

DADA R, KOTZE D, ELLERY W and UYS M (2007) WET-RoadMap. A Guide to the Wetland Management Series. WRC Report No. TT 321/07. Water Research Commission, Pretoria.

DEBANO LF and HANSEN WR (1989) Rehabilitating Depleted Riparian Areas Using Channel Structures. Practical Approaches to Riparian Resource Management. An Educational Workshop. American Fisheries Society, Bethesda MD. 141-148.

DIXON AB (2002) The hydrological impacts and sustainability of wetland drainage cultivation in Illubabor, Ethiopia. Land Degradation Dev. 13 17-31.

DIXON AB and WOOD AP (2003) Wetland cultivation and hydrological management in eastern Africa: Matching community and hydrological needs through sustainable wetland use. Nat. Resour. Forum 27 117-129.

ELLERY WN and KOTZE DC (2008) WET-OutcomeEvaluate, An evaluation of the rehabilitation outcomes at 6 wetland sites in South Africa. WRC Report No. TT 343/08. Water Research Commission, Pretoria.

KOTZE D and SILIMA V (2003) Wetland cultivation: Reconciling the conflicting needs of the rural poor and society at large through wetland wise use. Int. J. Ecol. Environ. Sci. 29 65-71.

GAVIN H (2003) Impact of ditch management on the water levels of a wet grassland in Southeast England. Agric. Ecosyst. Environ. 99 51-60.
GILMAN K (1994) Hydrology and Wetland Conservation. John Wiley and Sons, Chichester.

GRENFELL MC, ELLERY WN, GARDEN SE, DINI J and VAN DER VALK AG (2007) The language of intervention: A review of concepts and terminology in wetland ecosystem repair. Water SA 33 (1) 43-50.

McFARLANE MJ and WHITLOW R (1991) Key factors affecting the initiation and progress of gullying in dambos in parts of Zimbabwe and Malawi. Land Degradation Dev. 2 (3) 215-235.

McHUGH OV, MCHUGH AN, ELOUNDOU-ENYEGUE PM and STEEHUIS TS (2007) Integrated qualitative assessment of wetland hydrological and land cover changes in a data scarce dry Ethiopian highland watershed. Land Degradation Dev. 18 1-16.

MITSCH WJ and GOSSELINK JG (2007) Wetlands (4 $4^{\text {th }}$ edn.). John Wiley and Sons, Chichester. 600 pp.

MOORHEAD KK (2003) Effects of drought on the water-table dynamics of a southern Appalachian mountain floodplain and associated fen. Wetlands 23 (4) 792-799.

MUCINA L and RUTHERFORD MC (eds.) (2006) The Vegetation of South Africa, Lesotho and Swaziland. South African National Biodiversity Institute, Pretoria. 807 pp.

OWEN CR (1995) Water budget and flow patterns in an urban wetland. J. Hydrol. 169 171-187.

PATTERSON L and COOPER DJ (2007) The use of hydrologic and ecological indicators for the restoration of drainage ditches and water diversions in a mountain fen, Cascade Range, California. Wetlands 27 (2) 290-304.

POLLARD S, KOTZE D, ELLERY W, COUSINS T, MONARENG J, KING K and JEWITT G(2005) Linking water and livelihoods. The development of an integrated wetland rehabilitation plan in the communal areas of the Sand River Catchment as a test case. Association for Water and Rural Development, South Africa. URL: http://www.award.org.za/File uploads/File/WL\%20Phase\%20 I\%20final\%20report\%202005-2.pdf (Accessed December 2011).

PRESTON EM and BEDFORD BL (1988) Evaluating cumulative effects on wetland functions. A conceptual overview and generic framework. Environ. Manage. 12 565-583.

PRICE JS, HEATHWAITE AL and BAIRD AJ (2003) Hydrological processes in abandoned and restored peatlands. An overview of management approaches. Wetlands Ecol. Manage. 11 65-83.

RIDDELL ES, LORENTZ SA, ELLERY WN, KOTZE D, PRETORIUS JJ and NKETAR SN (2007) Water table dynamics of a severely eroded wetland system, prior to rehabilitation, Sand River Catchment, South Africa. In: Ribeiro L, Chambel A, Condesso de Melo MT (ed.) XXXV IAH Congress Groundwater and Ecosystems. Lisbon, Portugal.

RIDDELL ES, LORENTZ SA and KOTZE DC (2010) A geophysical analysis of hydro-geomorphic controls within a headwater wetland in a granitic landscape, through ERI and IP. Hydrol. Earth Syst. Sci. 14 1697-1713.

RIDDELL ES (2011) Characterisation of the hydrological processes and responses to rehabilitation of a headwater wetland of the Sand River, South Africa. PhD Thesis, University of KwaZulu-Natal, Pietermaritzburg, South Africa. 351 pp. URL: http://researchspace. ukzn.ac.za/jspui/handle/10413/3636.

SCHMIDT LJ and DEBANO LF (1990) Potential for enhancing riparian habitats in the Southwestern United States with watershed practices. For. Ecol. Manage. 33/34 385-403.

SCOONES I (1991) Wetlands in drylands: Key resources for agricultural and pastoral production in Africa. Ambio 20 (8) 366-371.

VOLDSETH RA, JOHNSON WC, GILMANOV T, GUNTENSPERGEN GR and MILLET BV (2007) Model estimation of land-use effects on water levels of northern prairie wetlands. Ecol. Appl. 17 (2) 527-540.

VON DER HEYDEN CJ and NEW MG (2003) The role of dambo hydrology of a catchment and the river network downstream. Hydrol. Earth Syst. Sci. 7 (3) 339-357.

WHITLOW R (1989) A review of dambo gullying in south-central Africa. Zambezia XVI (ii) 123-148. 